\title{
COMPARATIVE STUDY OF FISTULECTOMY BY CORING TECHNIQUE IN FISTULA IN ANO, USING RADIOFREQUENCY CAUTERY AND MONOPOLAR CAUTERY
}

\author{
Madhura M. Killedar ${ }^{1}$, S. H. Kulkarni², Honeypalsinh H. Maharaul ${ }^{3}$ \\ ${ }^{1}$ Associate Professor, Department of Surgery, Bharti Vidyapeeth University, Sangli. \\ 2 Professor, Department of Surgery, Bharti Vidyapeeth University, Sangli. \\ ${ }^{3}$ Senior Resident, Department of Surgery, Bharti Vidyapeeth University, Sangli.
}

\section{ABSTRACT}

Fistula in ano is common condition in perineal region. Anorectal fistulas are divided into four distinct types according to the Parks' classification: intersphincteric, transsphincteric, suprasphincteric, and extrasphincteric. ${ }^{1}$ The ultimate goal of fistula surgery is to eradicate it without disturbing or disturbing minimally the anal sphincter mechanism. The radiofrequency scalpel is an innovative instrument, which allows cutting and coagulating tissues in an atraumatic manner and which facilitates in accelerating and improving the surgical procedure conversely to the electric scalpel. ${ }^{2}$ This prospective study which will be conducted in a single centre and in this study we are comparing use of monopolar cautery and radiofrequency cautery units for the patients with fistula in ano operated during the period of February 2012 to February 2015. All fistulas will be treated by fistulectomy using coring technique. Results will be analyzed on following points like intraoperative bleeding, clearance of visual field, intra- and postoperative odema, and time required for every procedure, recurrence.

\section{AIMS AND OBJECTIVES OF STUDY}

1. To compare intraoperative bleeding during surgery using both the units (cautery/RF cautery) during surgery.

2. To assess clearance of field of vision intraoperatively.

3. To see for intraoperative and post-operative edema.

4. To assess time required for the procedure.

5. Final results in terms of recurrence.

\section{CONCLUSION}

Radiofrequency ablation is better method for fistulectomy compared to monopolar cautery in terms of intraoperative blood loss, post-operative pain, oedema, and healing period. But if procedure is better taken care of recurrence is avoidable. Operative time required for monopolar cautery exceeds radiofrequency cautery.

\section{KEYWORDS}

Fistula in Ano; Coring; Radiofrequency Cautery; Monopolar Cautery; Fistulectomy.

HOW TO CITE THIS ARTICLE: Madhura M. Killedar, S. H. Kulkarni, Honeypalsinh H. Maharaul. "Comparative Study of Fistulectomy by Coring Technique in Fistula in Ano, Using Radiofrequency Cautery and Monopolar Cautery." Journal of Evolution of Medical and Dental Sciences 2015; Vol. 4, Issue 99, December 10; Page: 16411-16413, DOI: 10.14260/jemds/2015/2431

\section{MATERIAL AND METHODS}

Data was collected from patients operated during the period February 2012 to February 2015 for fistula in ano and treated surgically for fistulectomy by coring technique without primary closure of the wound. The patients were randomly distributed for treatment by monopolar cautery (Called ' $M$ ' group) and for radiofrequency cautery (called 'R' group). Final outcome in the surgical procedure was in toto excision of the tract from external opening to internal opening. Wound was allowed to heal by secondary intention. Severity of edema on $5^{\text {th }}$ post-operative was assessed. Randomly selected 16 patients from each group. Data was collected in proforma and was analyzed.

\section{Inclusion Criteria}

All cases of fistula in ano of any duration in males or females of all age group with single or multiple external opening willing to undergo surgical procedure.

Financial or Other, Competing Interest: None.

Submission 17-11-2015, Peer Review 18-11-2015,

Acceptance 02-12-2015, Published 08-12-2015.

Corresponding Author:

Dr. Madhura M. Killedar,

Bharti Vidyapeeth Medical College and Hospital,

Wanlesswadi-416414, Sangli.

E-mail: mdhurakilledar@gmail.com

DOI:10.14260/jemds/2015/2431

\section{Exclusion Criteria}

1. Fistula in ano with Crohn's disease or H/o tuberculosis treated in past or suspicious of malignancy.

2. Patients with alcoholic cirrhosis, HIV positive, renal failure, pregnant women, inflammatory bowel disease.

3. Fistula in ano with recurrence.

4. High trans-sphincteric fistulas with or without high blind tract, suprasphincteric, extrasphincteric fistulas.

\section{Study Type}

The study is prospective comparative study of management of fistula in ano by fistulectomy with coring technique using radiofrequency cautery and monopolar cautery. Patients operated during the period of February 2012 to February 2015 for fistula in ano with above inclusive criteria were included in the study.

\section{RESULTS AND DISCUSSION}

An anorectal fistula (Fistula-in-Ano) is an abnormal communication between the anus and the perianal skin. ${ }^{1}$ Anal canal glands situated at the dentate line afford a path for infecting organisms to reach the intramuscular spaces. ${ }^{1}$ Fistulas can occur spontaneously or secondary to a perianal (Or perirectal) abscess. ${ }^{1,2}$

Fistulectomy is a surgical procedure where a fistulous tract is excised (Cut out) completely. This is compared with fistulotomy, where the fistulous tract is merely laid open to heal. ${ }^{3}$ 
Fistulectomy removes secondary fistulous tracts compared to fistulotomy, but fistulotomy has shorter healing times and less chance of damage to the sphincters. ${ }^{4}$ Monopolar Cautery works on principle of using high frequency electrical current passed from a single electrode where cauterization occurs; the patient's body serves as a ground. ${ }^{5}$ Radiofrequency works on principle of ablation of tissue using the heat generated from medium frequency alternating current (In the range of $350-500 \mathrm{KHz}){ }^{6}$

Radiofrequency ablation is generally conducted in the outpatient setting, using either local anesthetics or conscious sedation anesthesia. ${ }^{7}$ Two important advantages of RF current (Over previously used low frequency AC or pulses of DC) are that it does not directly stimulate nerves or heart muscle and therefore can often be used without the need for general anesthetic and that it is very specific for treating the desired tissue without significant collateral damage. ${ }^{7}$ It has been used for tumor ablation, varicose vein treatment, pain management. We have used same principle in management of Fistula-in ano.

Mean Age group of patient in each group was 35 years. There were 9 male and 7 female patients in the study Group M, while 10 male and 6 female in Group R (Figure 1).

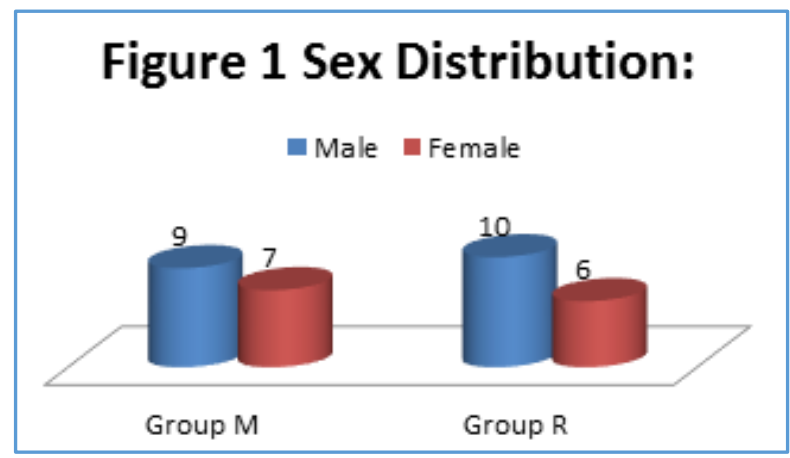

\section{Figure 2 :Blood Loss}

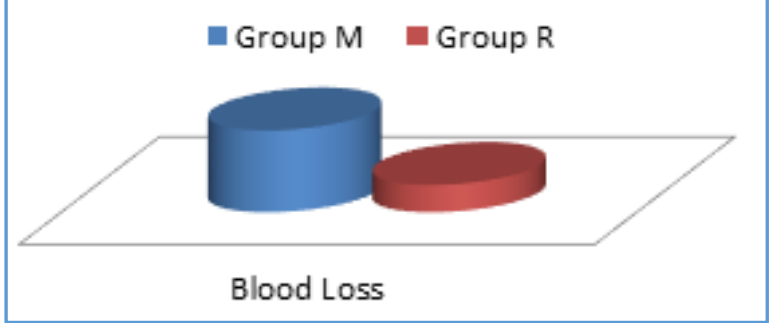

Intraoperative bleeding during surgery was about 30$34 \mathrm{ml}$ in Group $\mathrm{M}$ and $10-12 \mathrm{ml}$ in Group $\mathrm{R}$ suggesting that blood loss is less with radiofrequency while more with monopolar cautery. Time duration required for surgery in Group R was 30-35 min. while Group M was 15-20 min. (Figure 3).

\section{Figure 3 Duration Of Surgery}

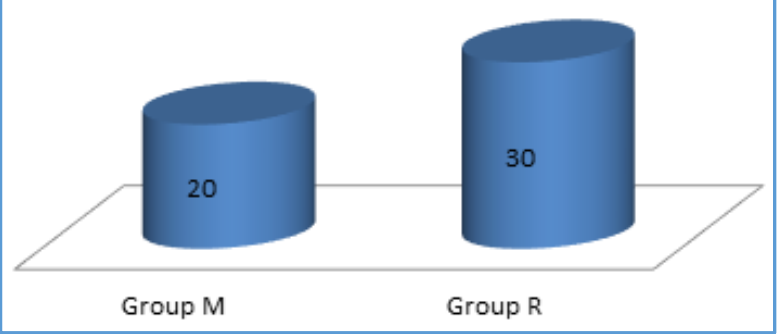

There was minimal edema in randomly selected 5 patients of Group R (Figure 4), while oedema was evident in all 5 patients of Group M (Figure 5). Duration of healing of fistula tract was 3-4 weeks in Group R, while it extended to 5-6 wks. in Group M. There was no evidence of recurrence in both groups.
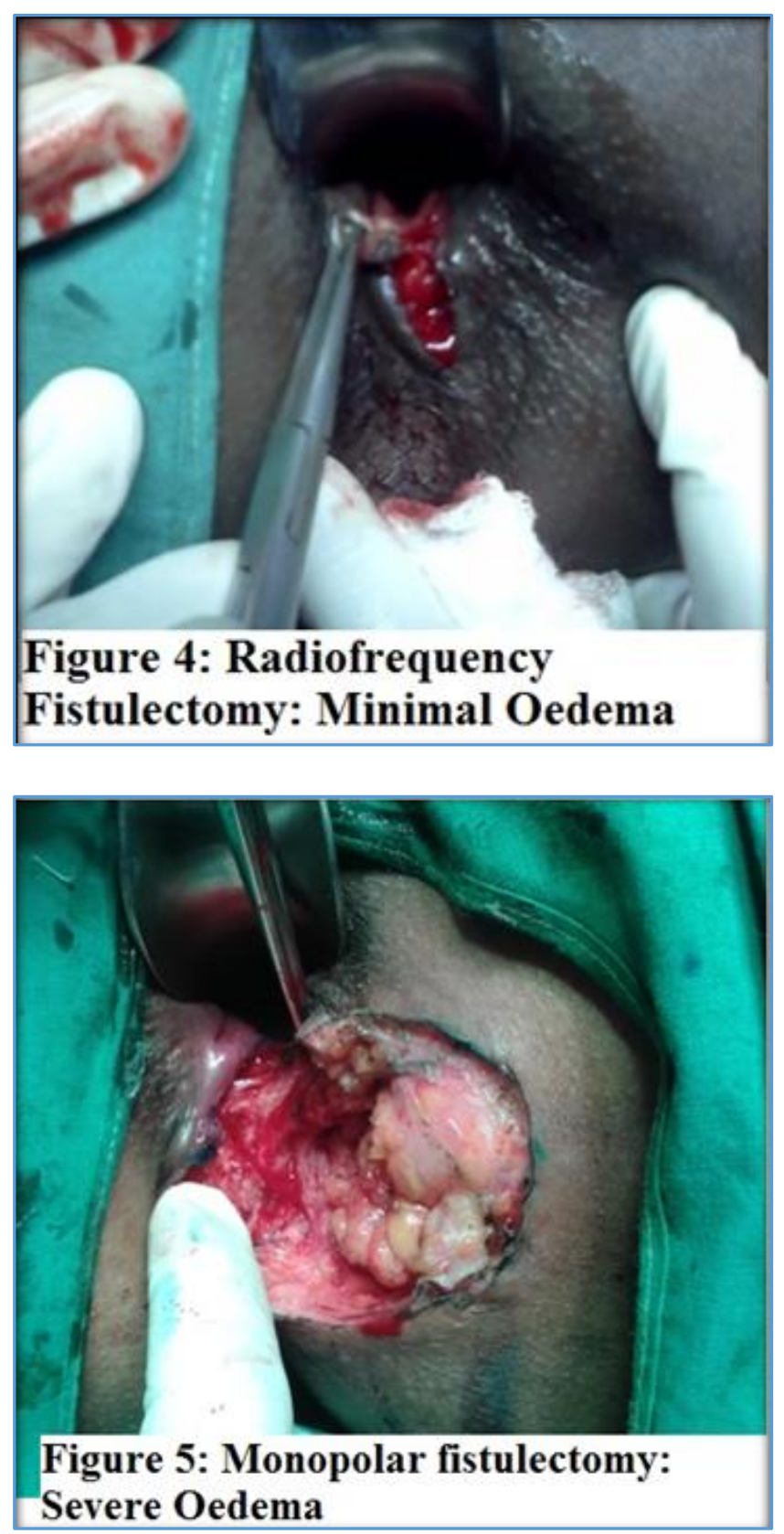

\section{CONCLUSION}

Radiofrequency ablation is better method for fistulectomy compared to monopolar cautery in terms of intraoperative blood loss, post-operative pain, oedema, healing period.

\section{REFERENCES}

1. http://fitsweb.uchc.edu/student/selectives/Luzietti/Pain ful_anus_fistula_in_ano.htm.

2. Filingeri V, Gravante G, Cassisa D. Department of Surgery, University of Rome Tor Vergata Rome (Italy); Clinical applications of radiofrequency in proctology: a review. European Review for Medical and Pharmacological Sciences, 2006;10:79-85. 
3. Jain, Bhupendra Kumar; Vaibhaw, Kumar; Garg, Pankaj Kumar; Gupta, Sanjay; Mohanty, Debajyoti (1 January 2012). "Comparison of a Fistulectomy and a Fistulotomy with Marsupialization in the Management of a Simple Anal Fistula: A Randomized, Controlled Pilot Trial." Journal of the Korean Society of Coloproctology 28(2):78.

4. Belmonte Montes, C; Ruiz Galindo, GH; Montes Villalobos, JL; Decanini Terán, C (Oct-Dec 1999). “[Fistulotomy vs fistulectomy. Ultrasonographic evaluation of lesion of the anal sphincter function]." Revista de gastroenterologia de Mexico 64(4):167-70.
5. http://medicaldictionary.thefreedictionary.com/monopolarcautery.

6. Sabiston textbook of surgery: the biological basis of modern surgical practice. (19th ed.). Philadelphia, PA: Elsevier Saunders. p. 236.

https://en.wikipedia.org/wiki/Radiofrequency_ablation. 